\title{
Repetition of suicide attempts across episodes of severe depression Behavioural sensitisation found in suicide group but not in controls
}

Louise Brådvik ${ }^{1 *}$, Mats Berglund ${ }^{2}$

\begin{abstract}
Background: Those who die by suicide and suffer from depression are known to have made more suicide attempts during their life-span as compared to other people with depression. A behavioural sensitisation or kindling model has been proposed for suicidal behaviour, in accordance with a sensitisation model of depressive episodes. The aim of the present study was to test such a model by investigating the distribution of initial and repeated suicide attempts across the depressive episodes in suicides and controls with a unipolar severe depression.
\end{abstract}

Method: A blind record evaluation was performed of 80 suicide victims and controls admitted to the Department of Psychiatry between 1956 and 1969 and monitored to 2010. The occurrence of initial and repeated suicide attempts by order of the depressive episodes was compared for suicides and controls.

Results: The risk of a first suicide attempt decreased throughout the later episodes of depression in both the suicide group $(p<.000)$ and control group $(p<.000)$. The frequencies of repetition early in the course were actually higher in the control group $(p<.007)$. After that, the risk decreased in the control group, while the frequencies remained proportional in the suicide group. At the same time, there was a significantly greater decreased risk of repeated attempts during later episodes in the control group as compared to the suicide group $(p<.000)$. The differences were found despite a similar number of episodes in suicides and controls.

Conclusion: Repeated suicide attempts in the later episodes of depression appear to be a risk factor for suicide in severe depression. This finding is compatible with a behavioural sensitisation of attempts across the depressive episodes, which seemed to be independent of a corresponding kindling of depression.

\section{Background}

Mood disorder is the single diagnosis with the greatest impact on suicide. In reviews of psychological autopsies it was concluded that an average of around $50 \%, 43 \%$ or $44 \%$ of all suicide victims had previously suffered from a depressive disorder [1-3].

Among depressed patients, suicide attempt is known to be a strong predictor for suicide [4-8]. Attempted suicide has been shown to be more likely when there are a higher number of depressive episodes [9] or more time spent in depression [10]. Furthermore, it has been concluded that once a suicide attempt has occurred, the

\footnotetext{
* Correspondence: louise@bradvik.se

'Department of Clinical Sciences Lund, Division of Psychiatry, Lund

University Hospital, Lund, Sweden

Full list of author information is available at the end of the article
}

patient is at high risk of more suicide attempts if future depressions occur [11].

Over the long-term course of depression, the onset of depressive episodes may become increasingly autonomous and less related to life-stressors $[12,13]$. This pattern has been hypothesised to result from a sensitisation process analogous to an animal electrophysiological model called "the kindling hypothesis" [14-16], or a behavioural sensitisation where every new episode gives rise to negative thinking patterns $[17,18]$.

Those models may be applicable to suicidal behaviour as well as depression, and a cognitive processing for suicidal behaviour has been proposed [19]. To some extent, this proposal was indirectly supported by a cross-sectional study, which showed that patients with only one previous suicide attempt showed a significant 
correlation between intensity of suicidal ideation and life stress within 12 months, while patients with multiple self-harm showed no such relationship [20]. In other words, suicidal ideation appeared to be independent of life-stressors in the case of multiple self-harm. Furthermore, apart from death wish, an acquired ability to enact lethal self-injury has been proposed as a precursor of serious suicidality [21]. Number of past suicide attempts have been shown to predict acquired capability of lethal self-injury [22] in agreement with this proposal. Other investigators have found number of suicide attempts associated with a greater severity of suicidal symptoms [23]. Also, one has proposed that the painful and fear-inducing qualities of suicidality may diminish with repetition, whereas opponent processes (e.g., calming and pain-relieving effects) may intensify [24], and people may engage in more and more extreme behaviour [25]. Other authors have found that those who had both planned and attempted suicide were more impulsive than those who made suicide attempts without prior planning [26]. This indicates that impulsivity may be a mediator of suicide attempt by increasing the capability of making suicide attempt. In contrast however, greater lethality of current suicide attempt was not significantly associated with number of attempts in one study [23]. In addition according to that study, there was no reduction of pre-attempt stress, as has been suggested in the kindling theory of suicidal behaviour. However, none of these studies was a longitudinal investigation into suicidal behaviour across the depressive episodes, and so there was no direct evidence of a behavioural sensitisation. Furthermore, to our knowledge, no previous study has examined a possible sensitisation of suicide attempts in relation to fatal suicidal behaviour.

We have previously shown that suicide attempt predicts suicide in severe depression independent of severity, violence or repetition of the attempt [7]. This difference was found despite the finding that there were high and similar rates of adequate antidepressant treatment and also improvement across the episodes in those who died by suicide and controls [27]. People who died by suicide and suffered from a unipolar depression appeared to make suicide attempts across the later episodes more often than controls, while those with a bipolar disorder showed no significant difference in rates of suicide attempts across the episodes between those who died by suicide and controls [28].

The aim of the present study was to investigate the occurrence of initial and repeated suicide attempts during different depressive episodes in those who died by suicide and controls with a unipolar severe depression. A behavioural sensitisation model would imply that suicide attempts would be repeated throughout the episodes. This was hypothesized to occur in the suicide group, but not in the control group.

\section{Materials and methods}

\section{The sample}

In the $1950 \mathrm{~s}$ and $1960 \mathrm{~s}$, all in-patients at the Department of Psychiatry, University Hospital, Lund were rated on a multiaxial diagnostic schedule at discharge [29]. This database enabled patients to be selected with a prospectively rated severe depression/melancholia for an investigation into suicide. The design of the sampling procedure is presented in a flow diagram (Figure 1). The very long-term follow up (to 2010) enabled a fairly high number of deaths by suicide to be investigated.

A total of 1,206 patients received the diagnosis severe depression/melancholia (506 men and 700 women). Their mortality was followed-up in three sessions: to January 1, 1984 to January 1, 1998, and to February 15, 2010. There were 116 suicide victims up to 2010. Out of these 103 had taken their lives up to 1984, another 11 up to 1998, and 2 more up to 2010.

The case records of those who died by suicide and matched controls from the total sample [30] were

\section{Secondary depressions excluded}

116 suicides $\longrightarrow 100$ suicides (primary depressions)

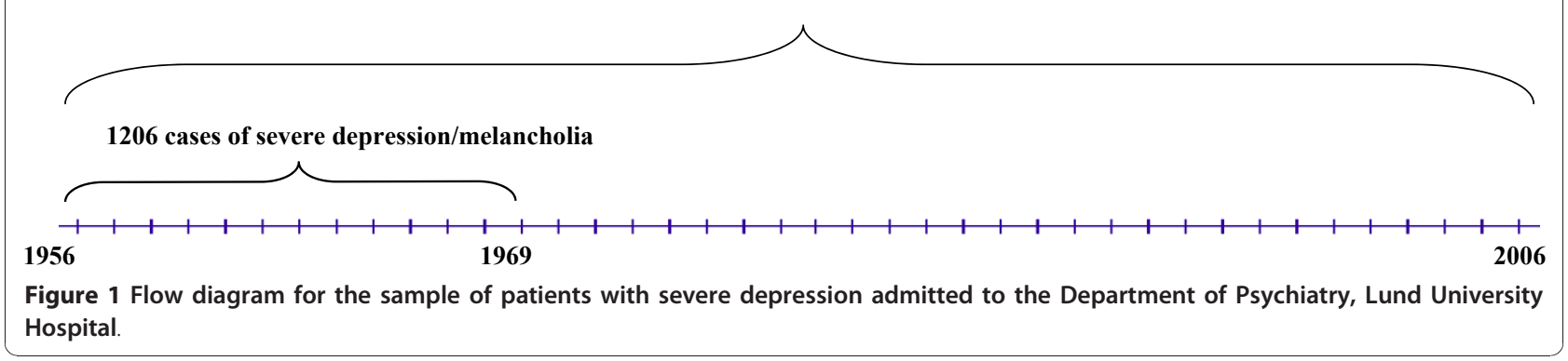


evaluated in detail. The researcher was unaware of the suicidal outcome and a similar procedure was carried out at second and third follow-up. A blind procedure allowed us to avoid the usual bias inherent in the retrospective evaluation. Secondary depressions were excluded according to Research Diagnostic Criteria [31], mainly alcoholism. Though alcohol dependence is related to a high risk of suicide [32,33], and is a major contributor to the suicide population [34,35], we excluded patients with primary alcohol dependence in order to study the contribution of depression alone on the suicidal outcome.

We obtained 100 deaths by suicide, 44 men and 56 women, with a primary severe depression. Matched controls, one for each suicide, were selected (from the total sample of 1,206 former in-patients of the Department of Psychiatry) using the criteria of diagnosis, gender, year of birth, and index admission year. The controls were chosen to be alive at the suicide death of the persons they matched and were monitored up to the time of death, so the length of follow-up was the same for both suicides and controls.

A retrospective diagnosis according to DSM-IV [36] was performed, based on the symptoms reported in the records. It turned out that $91 \%$ of the patients met the criteria for major depressive disorder with melancholic or psychotic features when in a depressive phase. Though the case-records were carefully written and very informative, individual symptoms might have been underreported, so the actual number was probably higher. Both the suicide group and the control group contained 20 patients who, at some time, had at least one episode of elevated mood, indicating bipolarity. There were 57 suicides and 57 controls that had an episode of psychotic depression at some time.

In the present study only the 80 suicide victims and 80 controls with a unipolar depression were investigated, as there had been no difference between suicides and controls in the decrease in suicide attempt rates in the bipolar group [28]. Though those with unipolar depression were not originally matched, they showed a similar age at index admission. There were 35 men in the suicide group and 36 in the control group and 45 and 44 women respectively in those groups.

\section{Suicide attempts}

Suicide attempt was first scored by severity on the basis of the schedules introduced by Motto [36] and Weisman [37], as described in two previous papers $[7,30]$.

We used a rather broad definition of self-harm, including what Motto [36] called suicidal gestures, cases where intent was difficult to determine on the basis of case records. The study started in 1984 and the same definitions were used in the two follow-ups in 1998 and
2010. Some more recent investigators also use a broad definition of self-harm without considering the degree of intent [39-41], which would include suicidal gestures and probably some aborted attempts (here ambivalent attempts). The latter have been described by Marzuk et al. [42] and have been associated with actual suicide attempts [43].

In the present sample, suicide attempt has, not unexpectedly, been found to be more common in the suicide group (46/80 versus 25/80), as reported before [28]. However, neither severity nor violence of method discriminated between those who died by suicide and controls [7]. (In the 2010 follow-up, 33\% of the individuals in the suicide group sometimes made severe attempts as opposed to $28 \%$ in the control group; $43 \%$ and $52 \%$ respectively made violent.) Consequently, we chose to include all suicide attempts in the analysis regardless of severity and violence.

\section{Course of depression}

The entire course of depression up to the deaths by suicide and a corresponding date for the matched control was evaluated. Those, who died by suicide and controls, both showed similar rates of episodes; an average of $3.88(+/-3.44)$ episodes for those who died by suicide and $3.76(+/-3.83)$ in the controls, and a median of 3 in both groups. It should be noted that the controls were not monitored after the suicide death they matched, and therefore the number of episodes in controls are compared for a certain time span and not for a life-time, so they may have more episodes later. (During follow-up of the total sample to 2010 none of the controls had died by suicide.) Treatment of depressive episodes was similar throughout the course of depression in those who died by suicide and controls, and so was improvement on treatment [27].

The study was approved by Lund University Medical Ethics Committee - 1985 and 2003.

\section{Statistics}

Poisson regressions of the number of suicide attempts (per person) as a function of episode number and group (suicide deaths versus controls) was performed, where the decrease by higher episode number may be different for suicide deaths and controls. The differences of the initial level were also calculated [44]. Pearson's chi-square test was used for comparisons between groups [45].

\section{Results}

\section{Repetition of suicide attempts}

In the suicide group, as mentioned above, 46 patients had made suicide attempts ( 21 men and 25 women) compared with 25 patients in the control group (11 
men, 14 women). Of these, $46 \%$ in the suicide group were repeaters compared with $40 \%$ in the control group. The average number of suicide attempts was 2.24 (SD +/- 2.77) in the suicide group and $2.32(\mathrm{SD}+/-3.61)$ in the control group

\section{Initial and repeated suicide attempt related to episode number}

Suicide attempts were separated into initial and repeated attempts. There was no significant difference between suicide deaths and controls in rates of suicide attempt during the first episode.

The risk of a first suicide attempt decreased throughout the later episodes of depression in both suicide deaths $(\mathrm{p}<.000)$ and controls $(\mathrm{p}<.000)$. No first suicide attempt occurred after the sixth episode in either group (Figure 2).

The difference in suicide attempts during the course of depressive episodes was found among repeated attempts (Figure 3). The frequencies of repetition early in the course were actually higher in the control group $(\mathrm{p}<.007)$. After that there was a decreased risk in the control group, while the frequencies remained proportional in the suicide group. Consequently, there was a significantly lower risk of repeated attempts during later episodes in the control group as compared to the suicide group $(\mathrm{p}<.000)$.

\section{Discussion \\ Main findings}

Repetition of suicide attempts throughout the course of depressive episodes was more common among those who died by suicide as compared with those who did not. Two models for the development of a progressive behavioural dysfunction in the course of mood disorders have been proposed: behavioural sensitisation and kindling [14-19]. Such models might explain the fact that those who later die by suicide appear to continue to make suicide attempts after their first attempt throughout the course of depressive episodes. To the best of our knowledge, the present study is the first to give clinical evidence of the hypothesised behavioural sensitisation of suicide attempts [19]. Furthermore, the difference between suicide deaths and controls indicates that the behavioural sensitisation or kindling of suicide attempts is related to a suicidal outcome.

However, early in the course, controls had shown higher rates of repetition. In a previous paper we have

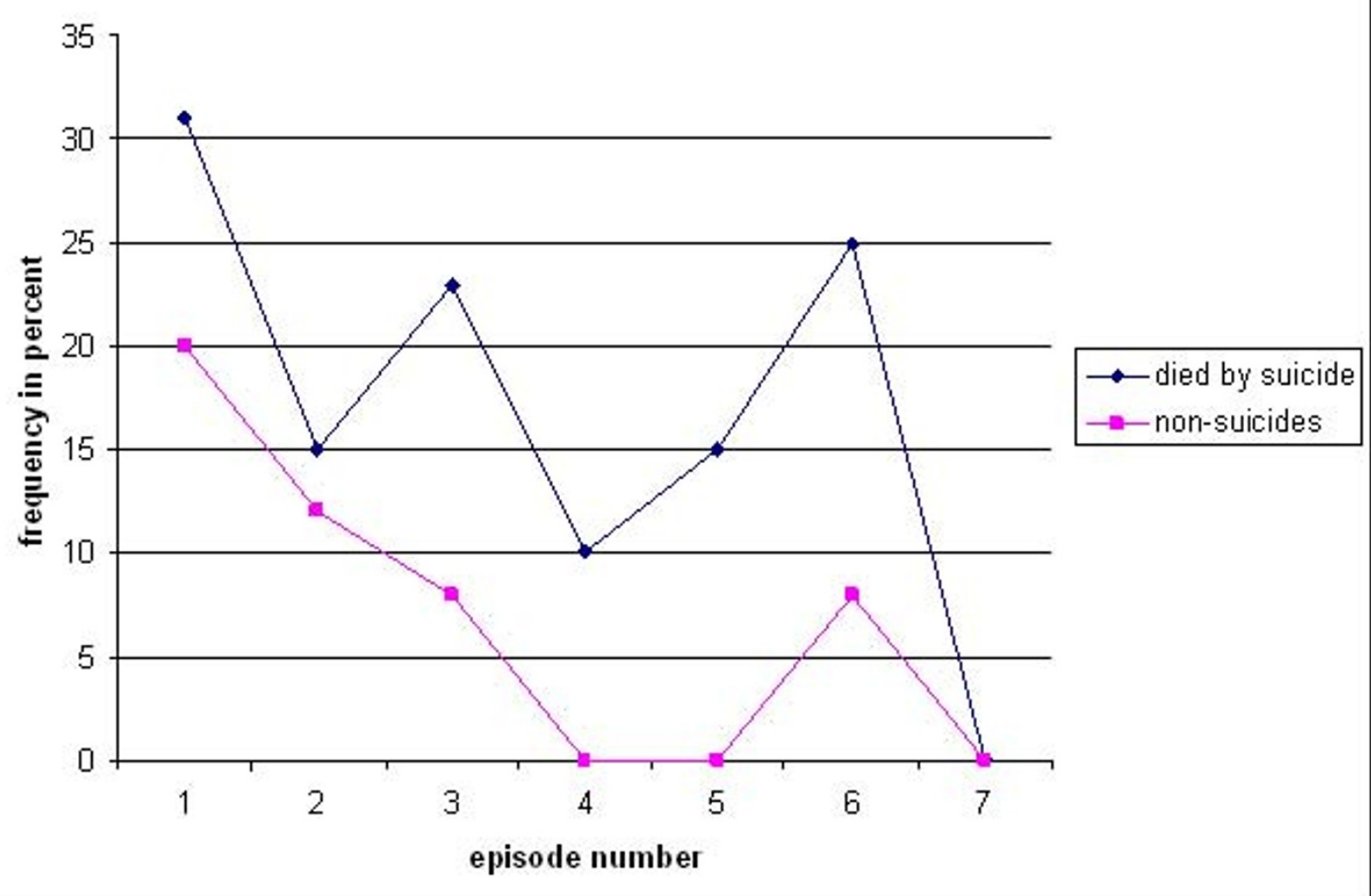

Figure 2 Occurrence of initial suicide attempt by episode in suicides and controls. 


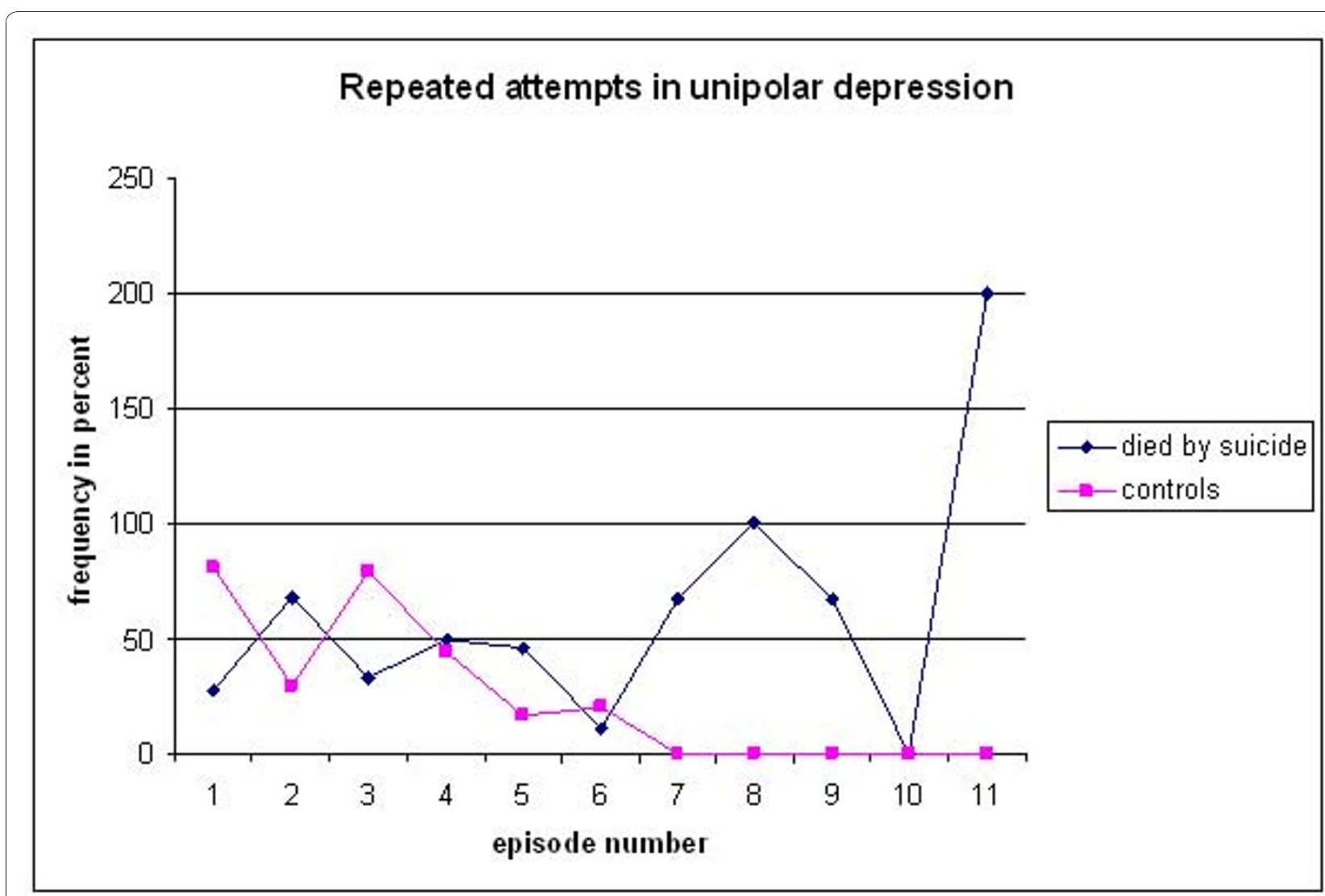

Figure 3 Occurrence of repeated suicide attempts by episode in suicides and controls

shown that repeated suicide attempts in the controls were related to external stressors [7]. This may explain the finding that repetition was more frequent early in the course in controls, as repeated attempts may occur as a reaction to life-stressors and cease for some people when the crisis is resolved. On the other hand, the continuation of repeated suicide attempts in the suicide group could perhaps be described as a behavioural sensitisation or kindling phenomenon.

Previous studies have shown a positive correlation between number of episodes of depression and occurrence of suicide attempt $[9,10,46]$. Those findings may indicate that suicide attempts are likely to occur throughout the course of depressive episodes. In a previous study we found more episodes to be a risk factor for suicide only if these were associated with suicide attempts [28], and that the difference was found in the unipolar group only in contrast to the bipolar group. In the present study, however, we found that only repeated attempts occurring throughout the depressive episodes in the unipolar group discriminated between suicide deaths and controls. On the other hand, no first suicide attempt occurred after the sixth depressive episodes, a fact that does not support the view that spending more time depressed increases the risk for a suicide attempt.

As mentioned above, this development of suicidal behaviour was found despite the fact that suicide deaths and controls showed a similar number of episodes. In other words there was no corresponding increase in number of episodes in the suicide group as compared to the control group. There were also similar rates of adequately treated episodes, as well as improvement, in both groups. Consequently, the difference does not appear to be secondary to a more severe course of depression with more frequent episodes in the suicide group, or secondary to less adequate treatment.

To sum up, we have found clinical evidence for a behavioural sensitisation of suicidal behaviour. This is similar to the long-postulated kindling of depressive episodes [14]. However, the behavioural sensitisation appeared to be independent of the course and treatment of depression and may be a phenomenon for suicidal behaviour on its own.

\section{Clinical implications}

Repeated suicide attempts in the later episodes of depression appear to be a risk factor for suicide in 
severe depression. Those who repeat in the later course should be treated with extra care.

\section{Strengths and limitations}

The present study was based on a fairly large sample of patients with a severe depression/melancholia, who had been rated on a multiaxial schedule at their first admission with this diagnosis and monitored for 37-50 years. The number of deaths by suicide was fairly high, 80 with a unipolar depression. The agreement of diagnostics with DSM-IV appeared to be high, with at least $91 \%$ fulfilling the diagnostic criteria for major depressive disorder with melancholic or psychotic features. Only primary depressions were included, while depressions secondary to other disorders (mainly alcoholism) were excluded. As no depression was secondary to alcohol abuse, the impact of alcohol abuse was diminished.

The fact that the sample constitutes patients with a severe depression makes it less representative of a general sample of depressed patients. However, these patients seem to be at a particularly high risk of suicide [47] and also appear to predominate among suicide deaths [34], and therefore they are worth studying.

The definition of suicide attempt was based on two old papers $[37,38]$, as the study started in 1984 . This would correspond to suicidal acts with intent to die with and without injuries according to more modern definitions $[40,41,48]$. However, suicidal gestures according to Motto were also included. Such were for instance ingestion of a smaller amount of pills, where intent to die was not clearly stated (but would account as selfinjury, as defined by O'Carroll - 48) or fetching a rope threatening to put around one's neck. Severity of attempt showed no correlation with fatal outcome, and therefore we included suicidal gestures in our analysis.

There were no personal interviews but only reports based on the case records. On the other hand, the suicide attempts have been continuously registered, thus minimising the recall bias inherent in interviews later in life. However, there is always a risk that some suicidal behaviour is never reported if there is no need for medical intervention. The crucial point is whether reports of repetition and severity are equally reliable for suicide deaths and controls. This could be assumed but not proven. The evaluation of the number of episodes was based on a blind evaluation of case records. The data about remission, recovery, relapse, and recurrence was based on reports of clinical evaluations. Once more, the reports were made at the time, thereby limiting the risk of recall bias. Furthermore, though there may be some uncertainty of the exact start of a new depressive episode, we do know the time sequence, i.e. we do know which suicide attempts occurred later in the course independent of the onset of a certain episode.

\section{Conclusion}

Repeated suicide attempts in the later episodes of depression appear to be a risk factor for suicide in severe depression. In contrast, controls made repeated attempts during the early course of depression.

The difference could not be considered to be secondary to a more severe course of depression, or due to a lack of treatment in the suicide group, but to a difference in suicidal behaviour itself.

The present study gives clinical evidence of a behavioural sensitisation or a kindling model of suicide attempt across the depressive episodes, independent of a corresponding kindling of depression. Furthermore, this sensitisation appears to be related to a suicidal outcome as it was found in the suicide group only.

\section{Acknowledgements}

Contract grant sponsors: Swedish Research Council; Sjöbring Fund; O.M Persson Memorial Fund, the Söderström-Königska Foundation, and the Public Health Services of Lund. Arne Frank assisted with the register followup. Anna Lindgren, Mathematical Statistics, Centre of Mathematical Sciences, provided statistical advice. Leslie Walke revised the language.

\section{Author details}

'Department of Clinical Sciences Lund, Division of Psychiatry, Lund University Hospital, Lund, Sweden. ${ }^{2}$ Department of Clinical Alcohol Research, University Hospital MAS, Malmö, Lund University, Sweden.

\section{Authors' contributions}

$L B$ initiated the study, contributed to the design and drafted the manuscript $M B$ contributed to the design. Both authors read the manuscript.

\section{Competing interests}

The authors declare that they have no competing interests.

Received: 12 October 2010 Accepted: 7 January 2011

Published: 7 January 2011

\section{References}

1. Lönnqvist JK: Psychiatric aspects of suicidal behaviour: depression. In The International Handbook of Suicide and Attempted Suicide. Edited by: Hawton K., Van Heeringen K. John Wiley 2000:107-120.

2. Arsenault-Lapierre G, Kim C, Turecki G: Psychiatric diagnoses in 3275 suicides: a meta-analysis. BMC Psychiatry 2004, 4:37.

3. Bertolote JM, Fleischmann A, De Leo D, Wasserman D: Psychiatric diagnoses and suicide: revisiting the evidence. Crisis 2004, 25:147-55, Review.

4. Sainsbury P: Depression, suicide and suicide prevention. In Suicide. Edited by: Roy A. William 1986:73-88.

5. Goldstein RB, Black DW, Nasrallah A, Winokur G: The prediction of suicide. Sensitivity, specificity, and predictive value of a multivariate model applied to suicide among 1906 patients with affective disorders. Arch Gen Psychiatry 1991, 48:418-22.

6. Nordström P, Asberg M, Aberg-Wistedt A, Nordin C: Attempted suicide predicts suicide risk in mood disorders. Acta Psychiatr Scand 1995, 92:345-50.

7. Brådvik L, Berglund M: Aspects of the suicidal career in severe depression. A comparison between attempts in suicides and controls. Arch Suicide Res 2002, 6:339-349.

8. Brådvik $L$, Berglund $M$ : Repetition and severity of suicide attempts across the life cycle. A comparison by age-groups between suicide victims and controls with a severe depression. BMC Psychiatry 2009, 9:62.

9. Ahrens B, Berghöfer A, Wolf T, Müller-Oerlinghausen B: Suicide attempts, age and duration of illness in recurrent affective disorders. J Affect Disord 1995, 36:43-49. 
10. Sokero TP, Melartin TK, Rytsälä HJ, Leskelä US, Lestelä-Mielonen PS, Isometsä ET: Prospective study of risk factors for attempted suicide among patients with DSM-IV major depressive disorder. Br J Psychiatry 2005, 186:314-8.

11. van Praag HM, Plutchik R: Increased suicidality in depression: group or subgroup characteristic? Psychiatry Res 1988, 26:273-278.

12. Kessing LV, Andersen EW, Andersen PK: Predictors of recurrence in affective disorder - analyses accounting for individual heterogeneity. J Affect Disord 2000, 57:139-45.

13. Kessing LV, Hansen MG, Andersen PK, Angst J: The predictive effect of episodes on the risk of recurrence in depressive and bipolar disorders a life-long perspective. Acta Psychiatr Scand 2004, 109:339-44.

14. Post RM, Rubinow DR, Ballenger JC: Conditioning and sensitisation in the longitudinal course of affective illness. Br J Psychiatry 1986, 149:191-201.

15. Kendler KS, Thornton LM, Gardner CO: Stressful life events and previous episodes in the etiology of major depression in women: an evaluation of the "kindling" hypothesis. Am J Psychiatry 2000, 157:1243-51.

16. Kessing LV: Severity of depressive episodes during the course of depressive disorder. Br J Psychiatry 2008, 192:290-3.

17. Teasdale JD: Negative thinking in depression: Cause, effect, or reciprocal relationship? Adv Behav Res Ther 1983, 5:3-25.

18. Teasdale JD: Cognitive vulnerability to persistent depression. Cogn Emot $1988,2: 247-74$

19. Lau MA, Segal ZV, Williams JM: Teasdale's differential activation hypothesis: implications for mechanisms of depressive relapse and suicidal behaviour. Behav Res Ther 2004, 42:1001-17.

20. Joiner TE, Rudd MD: Intensity and duration of suicidal crises vary as a function of previous suicide attempts and negative life events. J Consult Clin Psychol 2000, 68:909-16.

21. Joiner TE: Why people die by suicide? Harvard University Press, Cambridge, MA; 2005.

22. Van Orden KA, Witte TK, Gordon KH, Bender TW, Joiner TE Jr: Suicidal desire and the capability for suicide: tests of the interpersonalpsychological theory of suicidal behavior among adults. J Consult Clin Psychol 2008, 76:72-83.

23. Pettit JW, Joiner TE Jr, Rudd MD: Kindling and behavioral sensitization: are they relevant to recurrent suicide attempts? J Affect Disord 2004, 83:249-52.

24. Solomon RL: The opponent-process theory of acquired motivation: the costs of pleasure and the benefits of pain. Am Psychol 1980, 35:691-712.

25. Joiner TE Jr: The trajectory of suicidal behavior over time. Suicide Life Threat Behav 2002, 32:33-41, Review.

26. Witte TK, Merrill KA, Stellrecht NE, Bernert RA, Hollar DL, Schatschneider C, Joiner TE Jr: "Impulsive" youth suicide attempters are not necessarily all that impulsive. J Affect Disord 2008, 107:107-16.

27. Brådvik L, Berglund M: Long-term Treatment and Suicidal Behaviour in Severe Depression. ECT and Antidepressant Pharmacotherapy May Have Different Effects on the Occurrence and Seriousness of Suicide Attempts. Depress Anxiety 2006, 23:34-41.

28. Brådvik $L$, Berglund $M$ : Depressive episodes with suicide attempts in severe depression. Suicides and controls differ only in the later episodes of unipolar depression. Arch Suicide Res 2010, 14:363-367.

29. Essen-Möller E, Wohlfahrt S: Suggestions for the amendment of the official Swedish classification of mental disorder. Acta Psychiatr Scand Suppl 1947, 47:551-555.

30. Brådvik $L$, Berglund $M$ : Risk factors for suicide in melancholia. A case record evaluation of 89 suicides and their controls. Acta Psychiatr Scand 1993, 87:306-311.

31. Spitzer R, Endicott J, Robins E: Research diagnostic criteria. Arch Gen Psychiatry 1978, 35:773-82.

32. Berglund $M$ : Mortality in alcoholics related to clinical state at first admission. A study of 537 deaths. Acta Psychiatr Scand 1984, 70:407-16.

33. Wilcox HC, Conner KR, Caine ED: Association of alcohol and drug use disorders and completed suicide: an empirical review of cohort studies. Drug Alcohol Depend 2004, 76(Suppl):S11-9, Review.

34. Arsenault-Lapierre G, Kim C, Turecki G: Psychiatric diagnoses in 3275 suicides: a meta-analysis. BMC Psychiatry 2004, 4:37.

35. Brådvik L, Mattisson C, Bogren M, Nettelbladt P: Mental disorders in suicide and undetermined death in the Lundby study. The contribution of severe depression and alcohol dependence. Arch Suicide Res 2010, 14:266-275.
36. American Psychiatric Association: Diagnostic and Statistical Manual of Mental Disorders, DSM-IV. American Psychiatric Association, Washington, DC; Fourth 1994.

37. Motto JA: Suicide attempts. A longitudinal view. Arch Gen Psychiatry 1965, 13:516-520

38. Weisman AD, Worden JW: Risk-rescue rating in suicide attempt. Arch Gen Psychiatry 1972, 26:553-61.

39. Silverman MM, Berman AL, Sanddal ND, O'Carroll PW, Joiner TE: Rebuilding the tower of Babel: a revised nomenclature for the study of suicide and suicidal behaviors. Part 2: Suicide-related ideations, communications, and behaviors. Suicide Life Threat Behav 2007, 37:264-77.

40. Hawton K, Fagg GJ, Simkin S, Bale E, Bond A: Trends in deliberate selfharm in Oxford, 1985-1995. Implications for clinical services and the prevention of suicide. Br J Psychiatry 1997, 171:556-60.

41. Hawton K, Harriss L, Hall S, Simkin S, Bale E, Bond A: Deliberate self-harm in Oxford, 1990-2000: a time of change in patient characteristics. Psychol Med 2003, 33:987-95

42. Marzuk PM, Tardiff K, Leon AC, Portera L, Weiner C: The prevalence of aborted suicide attempts among psychiatric in-patients. Acta Psychiatr Scand 1997, 96:492-496.

43. Barber ME, Marzuk PM, Leon AC, Portera L: Aborted suicide attempts: a new classification of suicidal behavior. Am J Psychiatry 1998, 155:385-89.

44. Fleiss JL, Levin B, Paik MC: Statistical Methods for Rates and Proportions. New York: John Wiley \& Sons; 32003

45. Ferguson GA: Statistical Analysis in Psychology and Education. McGrawhill, London; 21966.

46. Zisook S, Lesser I, Stewart JW, Wisniewski SR, Balasubramani GK, Fava M, Gilmer WS, Dresselhaus TR, Thase ME, Nierenberg AA, Trivedi MH, Rush AJ: Effect of age at onset on the course of major depressive disorder. Am J Psychiatry 2007, 164:1539-46.

47. Brådvik L, Mattisson C, Bogren M, Nettelbladt P: Long-term Suicide Risk in Depression in the Lundby cohort 1947-1997 - severity and gender. Acta Psychiatr Scand 2008, 117:185-191.

48. O'Carroll PW, Berman AL, Maris RW, Moscicki EK, Tanney BL, Silverman MM Beyond the Tower of Babel: a nomenclature for suicidology. Suicide Life Threat Behav 1996, 26:237-52.

\section{Pre-publication history}

The pre-publication history for this paper can be accessed here: http://www.biomedcentral.com/1471-244X/11/5/prepub

doi:10.1186/1471-244X-11-5

Cite this article as: Brådvik and Berglund: Repetition of suicide attempts across episodes of severe depression Behavioural sensitisation found in suicide group but not in controls. BMC Psychiatry 2011 11:5.

\section{Submit your next manuscript to BioMed Central and take full advantage of:}

- Convenient online submission

- Thorough peer review

- No space constraints or color figure charges

- Immediate publication on acceptance

- Inclusion in PubMed, CAS, Scopus and Google Scholar

- Research which is freely available for redistribution 